\title{
Pengaruh Risiko Bisnis dan Ukuran Perusahaan Terhadap Struktur Modal dan Nilai Perusahaan
}

\author{
Mahfudzah Hidayati Rahmi ${ }^{1}$, Fifi Swandari ${ }^{2}$ \\ Universitas Lambung Mangkurat \\ Email: mhrmimi27@gmail.com
}

\begin{abstract}
This study aims to analyze the effect of business risk (X1) and firm size (X2) on firm value (Y) with capital structure $(Z)$ as intervening variables in manufacturing companies that are flat on the Indonesia Stock Exchange (IDX).

The research method used in this study uses path analysis to analyze direct and indirect effects. The population in this study are all manufacturing firm listed on the Indonesia Stock Exchange (BEI) for the period of 2016-2018, with the sampling technique using purposive sampling. The hypothesis of this study was analyzed using the SPSS application with multiple linear regression analysis techniques.

The results of the study concluded that business risk had no significant effect on capital structure. Firm size has a positive and significant effect on capital structure. Business risk has no significant effect on firm value. Firm size has a positive and significant effect on firm value. Capital structure has a positive and significant effect on firm value. Business risk has no significant effect on firm value through capital structure. Firm size has a positive and significant effect on firm value through capital structure.
\end{abstract}

Keywords: business risk, firm size, capital structure, firm value.

\section{Abstrak}

Penelitian ini bertujuan untuk menganalisis pengaruh risiko bisnis (X1) dan ukuran perusahaan (X2) terhadap nilai perusahaan $(\mathrm{Y})$ dengan struktur modal $(\mathrm{Z})$ sebagai variabel intervening pada perusahaan manufaktur yang terdatar di Bursa Efek Indonesia (BEI).

Metode penelitian yang digunakan daam penelitian ini menggunakan analisis jalur (path analysis) untuk menganalisis pengaruh secara langsung maupun pengaruh secara tidak langsung. Populasi dalam penelitian ini adalah seluruh perusahaan manufaktur yang terdaftar di Bursa Efek Indonesia (BEI) periode 2016-2018, dengan teknik pengambilan sampel menggunakan purposive sampling. Hipotesis penelitian ini di analisis menggunakan aplikasi SPSS dengan teknik analisis regresi linier berganda.

Hasil penelitian menyimpulkan bahwa risiko bisnis tidak berpengaruh signifikan terhadap struktur modal. Ukuran perusahaan berpengaruh positif dan signifikan terhadap struktur modal. Risiko bisnis berpengaruh tidak signifikan terhadap nilai perusahaan. Ukuran perusahaan berpengaruh positif dan signifikan terhadap nilai perusahaan. Struktur modal berpengaruh positif dan signifikan terhadap nilai perusahaan. Risiko bisnis tidak berpengaruh signifikan terhadap nilai perusahaan melalui struktur modal. Ukuran perusahaan berpengaruh positif dan signifikan terhadap nilai perusahaan melalui struktur modal.

Kata Kunci: risiko bisnis, ukuran perusahaan, struktur modal, nilai perusahaan.

(C) 2021 Jurnal Riset Inspirasi Manajemen dan Kewirausahaan

\section{PENDAHULUAN}

Pertumbuhan ekonomi memang tujuan yang ingin di capai oleh setiap negara. Indikator dari negara dikatakan berhasil dapat dilihat dari pertumbuhan ekonominya. Ekonomi yang bertumbuh secara pesat akan berdampak baik bagi suatu negara, salah satunya di Indonesia dapat dilihat pada Pertumbuhan Produk Domestik Bruto (PDB) memiliki laju pertumbuhan ekonomi yang menigkat dari tahun 2014-2108 (www.bps.go.id).

Pertumbuhan ekonomi di Indonesia sangat bergantung pada keunggulan atau daya saing sektor- 
sektor industri yang menjadi bagian dari pertumbuhan ekonomi. Sektor industri manufaktur tergolong dalam salah satu faktor yang memberikan kontribusi bagi pertumbuhan ekonomi di Indonesia.

Perusahaan memiliki tujuan untuk memperoleh laba dalam kaitannya mengoptimalkan nilai perusahaan. Nilai perusahaan dapat mencerminkan kinerja keuangan perusahaan karena nilai perusahaan memiliki dampak pada keinginan investor untuk berinvestasi pada perusahaan. Menurut Ayuba (2019) nilai perusahaan dapat menunjukkan kemampuan bisnis untuk memaksimalkan kekayaan pemegang saham. Nilai perusahaan dapat menggambarkan kecenderungan bisnis untuk tumbuh yang diterjemahkan de dalam kecenderungan investor untuk berinvestasi.

Nilai perusahaan dapat ditingkatkan melalui banyak faktor, yaitu profitabilitas, firm size, rasio likuiditas, struktur modal, risiko pada bisnis perusahaan dan sebagainya. Faktor-faktor tersebut di evaluasi agar dapat diukur kesesuaian kegunaannya, jadi akan membantu perusahaan memutuskan kebijakan yang tepat untuk meningkatkan kinerja perusahaan serta nilai perusahaan.

Perusahaan dalam menjalankan bisnisnya memerlukan dan yang banyak, dana yang digunakan baik berupa dana internal maupun eksternal. Istilah struktur modal berkaitan erat dalam proporsi utang dan modal. Hal ini sangat penting karena proporsi utang dan modal merupakan sumber dana perusahaan. Menurut Riyanto (2012:296) struktur modal sangat berpengaruh pada keuangan perusahaan dan pada akhirnya akan memberikan pengaruh pada nilai perusahaan.

Menjalankan aktivitas usaha kecil, besar maupun yang sudah sukses sekalipun, bukan tidak mungkin untuk tidak menghadapi kendala yang biasa disebut risiko bisnis. Menurut Margaretha (2014:67) risiko merupakan kemungkinan terjadinya hal yang merugikan. Risiko memliki arti probabilitas tidak mencukupinya membayar beban bunga, perusahaan akan mengalami kebangkrutan.

Perusahaan yang digolongkan besar atau kecil merupakan suatu skala dalam menilai ukuran perusahaan. Seberapa mampu perusahaan dalam melakukan kegiatan usahanya, baik berupa penjualan atas produk maupun jasa yang dimiliki perusahaan.
Penelitian pengaruh risiko bisnis dan ukuran perusahaan terhadap struktur modal dan nilai perusahaan telah banyak diteliti dan memiliki hasil yang berbeda-beda sehingga variabel ini masih dapat diteliti kembali. Penelitian Suadyan \& Wiagustini (2013) pada struktur modal memperoleh hasil risiko bisnis ada pengaruh negatif. Septiani \& Suaryan (2018), Sawitri \& Lestari (2015) pada struktur modal memperoleh hasil ukuran perusahaan mempunyai efek dan signifikan. Dewi \& Sudiartha (2017), Regina et al (2015) pada struktur modal memperoleh hasil ukuran perusahaan negatif tapi tidak signifikan. Sawitri \& Lestari (2015) pada struktur modal memperoleh hasil tidak ada pengaruh risiko bisnis.

Dewi \& Sujana (2019), Suadyana \& Wiagustini (2013) pada nilai perusahaan memperoleh hasil ada pengaruh negatif signifikan risiko bisnis. Ardana et al (2015), Septiana \& Suaryana (2018) pada nilai perusahaan memperoleh hasil tidak ada pengaruh risiko bisnis. Rudangga \& Sudiarta (2016), Prasetyorini (2012) pada nilai perusahaan memperoleh hasil ada pengaruh positif dari ukuran perusahaan. Winata (2018), Suadyana \& Wiagustini (2013), Regina et al (2015) pada nilai perusahaan memperoleh hasil ada pengaruh postifi signifikan struktur modal. Dewi \& Wirajaya (2013), Ayuba et al (2019) pada nilai perusahaan memperoleh hasil ada pengaruh negatif serta signifkan struktur modal.

\section{A. Kerangka Konseptual}

Berdasarkan penelitian terdahulu serta teori yang mendukung penelitian ini, maka dikembangkan menjadi sebuah kerangka konsep tual yang dapat dilihat pada gambar berikut :

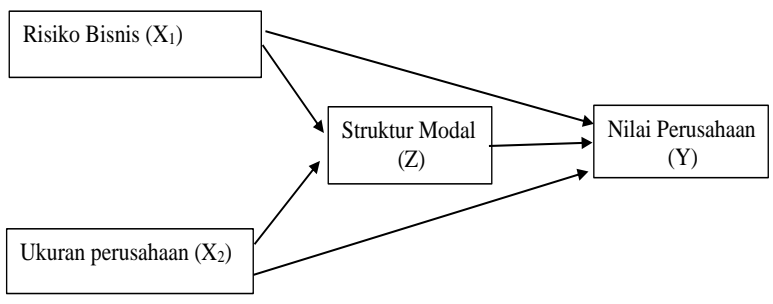

Gambar 1. Kerangka Konseptual

\section{B. Hipotesis Penelitian}

Berikut adalah hipotesis dalam penelitian ini:

H1: Risiko bisnis memiliki efek negatif terhadap struktur modal. 
https://ejurnal.stimi-bim.ac.id/index.php/JRIMK

H2: Ukuran perusahaan memiliki efek positif terhadap struktur modal.

H3: Risiko bisnis memiliki efek negatif terhadap nilai perusahaan.

H4: Ukuran perusahaan memiliki efek positif terhadap nilai perusahaan.

H5: Struktur modal memiliki efek positif terhadapnilai perusahaan.

H6: Risiko bisnis ada efek melalui struktur modal terhadap nilai perusahaan.

H7: Ukuran perusahaan ada efek melalui struktur modal terhadap nilai persahaan.

\section{METODE PENELITIAN}

Pengkajian ini tergolong dalam studi kuantitatif berdasarkan pada hubungan antar variabel dengan bentuk hubungan kausalitas. Menurut Arfan (2015:86), studi kausalitas adalah studi tentang menemukan akibat dari terjadinya sebab. Pengkajian ini memungut data dari Sebagian perusahaan yang termasuk dalam jenis data panel.

Sampel merupakan bagian dari populasi yang telah dipilih sesuai dengan karakteristik. Pemilihan sampel dapat mendukung maupun menurunkan nilai dari populasi, jadi saat pemilihan sampel harus dilakukan dengan baik-baik. Pemungutan sampel memakai Teknik purpose sampling. Purpose sampling adalah metode pemilihan sampel yang menjadi kriteria, antara lain :

1. Selama periode penelitian dari tahun 2016-2018 perusahaan manufaktur tidak mengalami kerugian.

2. Bermata uang Rupiah.

3. Industri yang tidak delisting oleh BEI.

\begin{tabular}{|c|c|c|}
\hline No. & Kriteria & Ket. \\
\hline \multicolumn{2}{|c|}{ Terdaftar di BEI } & 154 \\
\hline \multicolumn{3}{|c|}{ sampel yang dikeluarkan } \\
\hline 1. & $\begin{array}{l}\text { Perusahaan manufaktur yang } \\
\text { dijadikan sampel mengalami } \\
\text { kerugian selama periode } \\
\text { pengamatan 2016-2018. }\end{array}$ & 51 \\
\hline 2. & $\begin{array}{l}\text { Laporan keuangan perusahaan } \\
\text { manufaktur yang } \\
\text { menggunakan mata uang selain } \\
\text { rupiah. }\end{array}$ & 25 \\
\hline 3. & $\begin{array}{l}\text { Perusahaan yang delisting dari } \\
\text { Bursa Efek Indonesia }\end{array}$ & 4 \\
\hline
\end{tabular}

\begin{tabular}{lc}
\hline $\begin{array}{l}\text { Jumlah yang tidak memenuhi } \\
\text { kriteria }\end{array}$ & 80 \\
\hline Jumlah yang memenuhi kriteria & 74 \\
\hline $\begin{array}{l}\text { Jumlah seluruh pengamatan sampel } \\
\text { selama } 3 \text { tahun }\end{array}$ & 222 \\
\hline
\end{tabular}

Sumber: Data diolah (2019)

Penggunaan metode analisis data dilakukan dengan analisis path. Menurut Riduwan dan Kuncoro (2017) path menganilisis ikatan agar membaca imbas langsung dan tidak langsung bersama rangkaian ikatan variabel mandiri kepada variabel terikat. Berikut kegunaan analisis path menurut Riduwan dan Kuncoro (2017:2):

1. Memberikan penjelasan mengenai pelajaran atas fenomena masalah yang diteliti.

2. Memberikan nilai variabel terikat yang berdasarkan pada nilai yang didapat dari variabel dan memprediksi apakah penilitian ini bersifat kuantitatif denganmenggunakan analisi path.

3. Analisis path dapat digunakan dalam mekanisme jalur untuk mengukur besar pengaruh dari variabel terikat.

\section{HASIL PENELITIAN DAN PEMBAHASAN}

\section{A. Analisis Statistik Deskriptif}

Tabel 1 : Analisis Statistik Deskriptif

\begin{tabular}{lccccc}
\hline \multicolumn{1}{c}{ Variabel } & N & Min & Max & Mean & $\begin{array}{c}\text { Standar } \\
\text { Deviasi }\end{array}$ \\
\hline Risiko Bisnis & 222 & -131.197 & 349.000 & 3.83190 & 28.762398 \\
\hline Ukuran Perusahaan & 222 & 11.825 & 19.625 & 14.81789 & 1.542761 \\
\hline Struktur Modal & 222 & .080 & 4.770 & .91135 & .823414 \\
\hline Nilai Perusahaan & 222 & .001 & 82.440 & 3.33280 & 8.184235 \\
\hline
\end{tabular}

Sumber: Data diolah 2019

Risiko bisnis yang mempunyai nilai terendah -131.197 Indo Acidatama tahun 2017, artinya risiko bisnis yang tinggi ada pada Indo Acidatama. Risiko bisnis tertinggi sebesar 349.000 yang dimiliki oleh PT Voksel Electric tahun 2016, artinya risiko bisnis yang rendah ada pada PT Voksel Electric. Risiko bisnis disini punya nilai rata-rata sebesar 3.83910.

Ukuran perusahaan punya nilai terendah 11.825 ada pada PT Alaska Industrino tahun 2016. Nilai tertinggi 19.625 ada pada PT Astra International tahun 2018. Ukuran perusahaan disini punya nilai rata-rata sebesar 14.81789 . 
https://ejurnal.stimi-bim.ac.id/index.php/JRIMK

Struktur modal punya nilai terendah 0.080 ada pada PT Industri Jamu dan Farmasi Sido Muncul tahun 2016. Amgks tertinggi 4.770 ada pada PT Multi Bintang Indonesia tahun 2016. Struktur modal disini punya nilai rata-rata sebesar 0.91135 .

Nilai perusahaan punya nilai terendah 0.001 ada pada PT Wilmar Cahaya Indonesia tahun 2016. Nilai perusahaan tertinggi 82.440 ada pada PT Unilever Indonesia tahun 2017. Nilai perusahaan disini punya nilai rata-rata sebesar 82.440 .

\section{B. Uji Asumsi Klasik}

\section{Uji Normalitas}

Tabel 2 : Uji Normalitas

\begin{tabular}{lr}
\hline \multicolumn{1}{c}{ Keterangan } & $\begin{array}{c}\text { Unstandardiz ed } \\
\text { Residual }\end{array}$ \\
\hline $\mathrm{N}$ & 222 \\
Kolmogorov-Smirnov Z & .967 \\
Asymp. Sig. (2-tailed) & .307 \\
\hline Sumber: Data dioalah 2019
\end{tabular}

\section{Sumber: Data dioalah 2019}

Hasil pengujian Tabel 2 menunjukkan bahwa jumlah observasi Kolmogorov-Smirnov penelitian sebesar 222. Besarnya nilai Kolmogorov-Smirnov adalah 0,967 dengan Asymp. Sig. (2-tailed) 0,307. Angka Asymp. Sig. (2-tailed) yang berada diatas 0,05 menunjukkan data adalah berdistribusi normal.

\section{Uji Multikolinearitas}

Tabel 3 : Uji Multikolinearitas

\begin{tabular}{lccc}
\hline \multicolumn{1}{c}{ Variabel } & $\begin{array}{c}\text { Tole- } \\
\text { Rance }\end{array}$ & $\begin{array}{c}\text { Variance } \\
\text { Inflation } \\
\text { Factor }\end{array}$ & Keterangan \\
\hline Risiko Bisnis $\left(\mathrm{X}_{1}\right)$ & 0,993 & 1,007 & $\begin{array}{c}\text { bebas } \\
\text { multikolinearitas }\end{array}$ \\
\hline $\begin{array}{l}\text { Ukuran } \\
\text { Perusahaan }\left(\mathrm{X}_{2}\right)\end{array}$ & 0,986 & 1,003 & $\begin{array}{c}\text { bebas } \\
\text { multikolinearitas }\end{array}$ \\
\hline Struktur Modal $(\mathrm{Z})$ & 0,963 & 1,039 & $\begin{array}{c}\text { bebas } \\
\text { multikolinearitas }\end{array}$ \\
\hline
\end{tabular}

\section{Sumber data: diolah 2019}

Tabel 2, menunjukkan bahwa penelitian ini tidak terdapat gejala multikolinearitas karena semua pertimbangan dan syarat-syarat penelitian uji multikolinearitas sudah terpenuhi.
3. Uji Heteroskedastisitas

Tabel 3 : Uji Heteroskedastisitas Menggunakan Glejser

\begin{tabular}{lcc}
\hline \multicolumn{1}{c}{ Variabel } & Signifikan & Keterangan \\
\hline Risiko Bisnis $\left(\mathrm{X}_{1}\right)$ & 0,396 & Tidak ada gejala \\
\hline Ukuran Perusahaan $\left(\mathrm{X}_{2}\right)$ & 0,354 & Tidak ada gejala \\
\hline Struktur Modal $(\mathrm{Z})$ & 0,004 & Ada gejala \\
\hline
\end{tabular}

Sumber data: diolah 2019

Ada tidaknya heteroskedastisitas dapat diketahui jika nilai signiikasi antara variabel independent dengan absolut lebih dari 0,05 maka tidak terjadi masalah heteroskedastsitas. Struktur modal memliki nilai signifikan sebesar 0,004 yang dibawah nilai absolut kurang dari 0,05 maka dilakukan pengujian menggunakan uji spearman rho yang maksudnya mengkorelasikan nilai-nilai seluruh faktor terhadap nilai Unstandardized Residual, sehingga didapatkan hasil uji sebagai berikut:

Tabel 4 : Uji Heteroskedastisitas Menggunakan Uji Sperman Rho

\begin{tabular}{lcc}
\hline \multicolumn{1}{c}{ Variabel } & Signifikan & Keterangan \\
\hline Risiko Bisnis $\left(\mathrm{X}_{1}\right)$ & 0,516 & Tidak ada gejala \\
\hline Ukuran Perusahaan $\left(\mathrm{X}_{2}\right)$ & 0,943 & Tidak ada gejala \\
\hline Struktur Modal $(\mathrm{Z})$ & 0,061 & Tidak ada gejala \\
\hline
\end{tabular}

Sumber data: diolah 2019

Hasil Tabel 4, memperlihatkan seluruh faktor penelitian tidak memiliki gejala heteroskedastisitas, karena nilai signifikan yang dihasil adalah melebihi 0,05 .

\section{Uji Autokorelasi}

\section{Tabel 5 : Uji Autoloreasi}

\begin{tabular}{ccc}
\hline $\mathrm{dU}$ & $\mathrm{DW}$ & $4-\mathrm{dU}$ \\
\hline 1,799 & 1,836 & 2,201 \\
\hline
\end{tabular}

Sumber data: diolah 2019

Berdasarkan Tabel 5.5, angka Durbin Watson dalam model regresi sebesar 1,836 terletak batas antara upper bound (du) dan (4 du), artinya sama dengan nol dan tidak ada autokorelasi. 


\section{Analisis Regresi Linier Berganda}

Hasil regresi dengan tingkat signifikan $(\alpha)$ sebesar $5 \%$.

Tabel 6

Hasil Regresi

\begin{tabular}{lllll}
\hline Variabel & $\begin{array}{l}\text { Koef. } \\
\text { Reg. }\end{array}$ & thitung & Sig. & Ket. \\
\hline $\begin{array}{l}\text { Model 1 } \\
\text { (Pengaruh terhadap struktur modal) }\end{array}$ & & \\
Konstanta & $-0,500$ & & & \\
\hline $\begin{array}{l}\text { Risiko } \\
\text { Bisnis }\left(\mathrm{X}_{1)}\right.\end{array}$ & 0,002 & 1,194 & 0,234 & $\begin{array}{l}\text { Tidak } \\
\text { Signifikan }\end{array}$ \\
\hline $\begin{array}{l}\text { Ukuran } \\
\text { Perusahaan } \\
\left(\mathrm{X}_{2}\right)\end{array}$ & 0,095 & 2,674 & 0,008 & Signifikan \\
\hline
\end{tabular}

Model 2

(Pengaruh terhadap nilai perusahaan)

Konstanta $\quad-16,468$

\begin{tabular}{lcccl}
\hline $\begin{array}{l}\text { Risiko } \\
\text { Bisnis }\left(\mathrm{X}_{1)}\right.\end{array}$ & $-0,014$ & $-0,879$ & 0,381 & $\begin{array}{l}\text { Tidak } \\
\text { signifikan }\end{array}$ \\
\hline $\begin{array}{l}\text { Ukuran } \\
\begin{array}{l}\text { Perusahaan } \\
\left(\mathrm{X}_{2}\right)\end{array}\end{array}$ & 1,008 & 3,465 & 0,000 & Signifikan \\
\hline $\begin{array}{l}\text { Struktur } \\
\text { Modal (Z) }\end{array}$ & 5,395 & 9,866 & 0,000 & Signifikan \\
\hline
\end{tabular}

Sumber data: diolah 2019

Secara matematis regresi linier berganda dinyatakan dengan persamaan berikut:

1. Persamaan pertama $Z=-0,500+0,002 X_{1}+$ $0,095 \mathrm{X}_{2}+\varepsilon$

Interpretasi persamaan tersebut adalah sebagai berikut:

1. Nilai konstanta $-0,500$ menunjukkan jika tidak ada kenaikan nilai dari variabel mandiri kepada struktur modal (Z) -0,500.

2. Risiko bisnis $\left(\mathrm{X}_{1}\right)$ memberi dampak pada struktur modal (Z) 0,002, artinya kenaikan risiko bisnis sebesar 1 satuan akan menaikkan struktur modal (Z) 0,002.

3. Ukuran perusahaan $\left(\mathrm{X}_{2}\right)$ memberi dampak pada struktur modal (Z) 0,095, artinya kenaikan ukuran perusahaan $\left(\mathrm{X}_{2}\right)$ sebesar 1 satuan akan menaikkan struktur modal (Z) 0,095 .

2. Persamaan kedua $\mathrm{Y}=-16,468-0014 \mathrm{X}_{1}+$ $1,008 \mathrm{X}_{2}+5,395 \mathrm{Z}+\varepsilon$
Interpretasi persamaan tersebut adalah sebagai berikut :

1. Nilai konstanta $-16,466$ menjelaskan jika tidak ada kenaikan nilai pada risiko bisnis $\left(\mathrm{X}_{1}\right)$, ukuran perusahaan $\left(\mathrm{X}_{2}\right)$, dan struktur modal (Z), maka nilai perusahaan $(\mathrm{Y})$ menjadi -16,466

2. Risiko bisnis $\left(\mathrm{X}_{1}\right)$ memberi pengaruh $-0,014$ pada nilai perusahaan (Y), artinya kenaikkan risiko bisnis $\left(\mathrm{X}_{1}\right) 1$ satuan, akan menaikkan 0,014 pada nilai perusahaan $(\mathrm{Y})$.

3. Ukuran perusahaan $\left(\mathrm{X}_{2}\right)$ memberi pengaruh 1,008 pada nilai perusahaan $(\mathrm{Y})$, artinya kenaikkan ukuran perusahaan $\left(\mathrm{X}_{2}\right)$ 1 satuan akan menaikkan 1,008 pada nilai perusahaan (Y).

4. Struktur modal (Z) memberi pengaruh 5,395 pada nilai perusahaan (Y), artinya kenaikkan struktur modal (Z) 1 satuan menaikkan 5,395 pada nilai perusahaan (Y).

\section{Hasil Pengujian Hipotesis}

$\mathrm{H}_{1}=$ Risiko bisnis berpengaruh negatif pada struktur modal.

Hasil penelitian risiko bisnis $\left(\mathrm{X}_{1}\right)$ pada struktur modal, memperlihatkan nilai thitung sebesar 1,194 dan tingkat signifikan 0,234. Artinya, Risiko Bisnis $\left(\mathrm{X}_{1}\right)$ pada Struktur Modal ( $Z$ ) tidak ada pengaruh signifikan. Bukti dari pernyataan ini ialah $(1,194<$ 1,971) dan hasil signifikansi memperoleh hasil $(0,234$ $>0,05)$, maka uji ini ditolak.

$\mathrm{H}_{2}=$ Ukuran perusahaan berpengaruh positif pada struktur modal.

Hasil penelitian ukuran perusahaan $\left(\mathrm{X}_{2}\right)$ pada struktur modal, memperlihatkan nilai $\mathrm{t}_{\text {hitung }}$ sebesar 3,674 dan tingkat signifikan 0,008. Artinya Ukuran Perusahaan $\left(\mathrm{X}_{2}\right)$ pada Struktur Modal (Z) ada pengaruh signifikan. Bukti dari pernyataan ini ialah $(2,674>1,971)$ dan hasil signifikan memperoleh hasil $(0,008<0,05)$, maka uji ini diterima.

$\mathrm{H}_{3}=$ Risiko bisnis berpengaruh negatif pada nilai perusahaan.

Hasil penelitian risiko bisnis $\left(\mathrm{X}_{1}\right)$ pada nilai perusahaan, memperlihatkan nilai $t_{\text {hitung }}$ sebesar 0,879 dan tingkat signifikan sebesar 0,381. Artinya Risiko Bisnis $\left(\mathrm{X}_{1}\right)$ pada Nilai Perusahaan (Y) tidak berpengaruh. Bukti dari pernyataan ini ialah $(-0,879$ 
$<1,971)$ dan hasil signifikan $(0,381>0,05)$. Nilai negatif (-) menunjukkan pengaruh risiko bisnis akan berdampak berlawanan terhadap nilai perusahaan dan hipótesis ini ditolak.

$\mathrm{H}_{4}=$ Ukuran perusahaan berpengaruh positif terhadap nilai perusahaan.

Hasil penelitian ukuran perusahaan $\left(\mathrm{X}_{2}\right)$ pada nilai perusahaan, memperlihatkan nilai $t_{\text {hitung }}$ sebesar 3,465 dan tingkat signifikan sebesar 0,000. Artinya Ukuran Perusahaan $\left(\mathrm{X}_{2}\right)$ pada Nilai Perusahaan $(\mathrm{Y})$ ada pengaruh signifikan. Bukti dari pernyataan ini ialah $(3,465>1,971)$ dan hasil signifikan $(0,000<$ $0,05)$, maka uji ini diterima.

$\mathrm{H}_{5}=$ Struktur modal berpengaruh positif terhadap nilai perusahaan

Hasil penelitian struktur modal (Z) pada nilai perusahaan, memperlihatkan nilai $t_{\text {hitung }}$ sebesar 9,866 dan tingkat signifikan sebesar 0,000. Artinya Struktur Modal (Z) pada Nilai Perusahaan (Y) ada pengaruh signifikan. Bukti dari pernyataan ini ialah $(9,866>$ $1,971)$ dan hasil signifikan $(0,000<0,05)$, maka uji ini diterima.

\section{E. Analisis Path}

Analisis path pada penelitian ini ada dua hipotesi karena panelitian ini menggunakan dua variabel independen yaitu : hipotesis keenam $\left(\mathrm{H}_{6}\right)$ risiko bisnis melalui struktur modal ada pengaruh negatif pada nilai perusahaan dan hipotesis ketujuh $\left(\mathrm{H}_{7}\right)$ Ukuran perusahaan melalui struktur modal ada pengaruh positif pada nilai perusahaan. Model analisis path penelitian ini dinyatakan dalam persamaan berikut :

$Y=-16,468+0,079.0,543+0,177.0,543+0,543$ $+\varepsilon$

$Y=-16,468+0,043+0,096+\varepsilon$

Interpretasi persamaan tersebut adalah sebagai berikut:

1. Nilai konstanta sebesar $-16,468$ menyatakan tidak ada kenaikan nilai dari risiko bisnis $\left(\mathrm{X}_{1}\right)$, ukuran perusahaan $\left(\mathrm{X}_{2}\right)$, dan struktur modal (Z), maka nilai perusahaan (Y) -16,466.

2. Risiko bisnis $\left(\mathrm{X}_{1}\right)$ ada pengaruh pada nilai perusahaan (Y) melalui struktur modal (Z) 0,043 , artinya kenaikkan risiko bisnis $\left(\mathrm{X}_{1}\right)$ sebesar 1 satuan akan menaikkan 0,043 pada nilai perusahaan $(\mathrm{Y})$.
3. Ukuran perusahaan $\left(\mathrm{X}_{2}\right)$ ada pengaruh pada nilai perusahaan $(\mathrm{Y})$ melalui struktur modal (Z) 0,096, artinya kenaikkan ukuran perusahaan $\left(\mathrm{X}_{2}\right)$ sebesar 1 satuan akan menaikkan 1,008 pada nilai perusahaan $(\mathrm{Y})$.

$\mathrm{H}_{6}=$ Risiko bisnis melalui struktur modal ada pengaruh negatif terhadap nilai perusahaan

Pengujian hipotesis pengaruh tidak langsung adalah dengan melakukan analisis uji path (analisis jalur), yaitu dengan memperhitungkan koefisien masing-masing jalur yang diukur berdasarkan hipotesis, yaitu berdasarkan hasil analisis pengaruh langsung sebagai berikut:

1. Pengaruh langsung risiko bisnis pada nilai perusahaan ialah $-0,048$.

2. Pengaruh langsung risiko bisnis pada struktur modal ialah 0,079

3. Pengaruh langsung dari struktur modal pada nilai perusahaan ialah 0,543

Analisis jalur (path analysis) perhitungan pengaruh tidak langsung, yaitu $\mathrm{X} 1$ melalui $\mathrm{Z}$ terhadap $\mathrm{Y}=0,079 \times 0,543=0,043$. Menurut Akdon (2017: 117) hasil dari pengujian secara tidak langsung tersebut dapat diketahui signifikansinya melalui perhitungan tabel $\mathrm{F}$ secara manual, dengan rumus berikut:

$$
\mathrm{F}=\frac{(\mathrm{n}-\mathrm{k}-1) \mathrm{R}^{2}}{\mathrm{k}\left(1-\mathrm{R}^{2}\right)}
$$

$$
\begin{aligned}
& \text { Keterangan : } \\
& \mathrm{n} \quad=\text { jumlah sampel } \\
& \mathrm{k} \quad=\text { jumlah variabel } \text { eksogen } \\
& \mathrm{R}^{2} \quad=\mathrm{R}_{\text {Square }}
\end{aligned}
$$

Ketika $\mathrm{F}_{\text {hitung }} \geq \mathrm{F}$ tabel, maka tolak Ho artinya signifikan dan pada saat $\mathrm{F}$ hitung $\leq \mathrm{F}$ tabel terima Ho artinya tidak signifikan. Sebelum menggunakan rumus tabel $\mathrm{F}$, ketahui terlebih dahulu $\mathrm{R}^{2}$, berikut perhitungannya :

$$
\begin{array}{ll}
\mathrm{X} 1-\mathrm{Z}-\mathrm{Y} & =-0,048+0,043 \\
\mathrm{R} & =-0,005 \\
\mathrm{R}^{2} & =0,00003
\end{array}
$$

Setelah hasil $\mathrm{R}^{2}$ sudah diketahui maka pengukuran signifikansi pengaruh tersebut dapat di di hitung dengan cara memperbandingkan nilai $\mathrm{F}_{\text {hitung }}$ dengan nilai $\mathrm{F}_{\text {tabel }}$ :

$$
\mathrm{F}=\stackrel{(\mathrm{n}-\mathrm{k}-1) \mathrm{R}^{2}}{ }
$$




\begin{aligned} \hline \hline $\mathrm{F}= & \frac{(222-2-1) 0,00003}{2(1-0,00003)} \\ & \frac{0,006}{2,000} \\ & =0,003\end{aligned}$

Nilai $F_{\text {hitung }}$ tersebut selanjutnya dibandingkan dengan nilai $F_{\text {tabel }}(D F=222$ sebesar 2,646) maka dapat diketahui bahwa nilai $(0,003<2,646)$ menunjukkan bahwa nilai $\mathrm{F}_{\text {hitung }}$ lebih kecil dari nilai $F_{\text {tabel }}$ yang artinya risiko bisnis tidak memberikan pengaruh untuk nilai perusahaan melalui struktur modal, hasil uji ini ditolak.

$\mathrm{H}_{7}=$ Ukuran perusahaan melalui struktur modal berpengaruh positif terhadap nilai perusahaan

Hasil koefisien masing-masing jalur berdasarkan hipotesis analisis pengaruh langsung sebagai berikut:

1. Pengaruh langsung Ukuran Perusahaan terhadap Nilai Perusahaan bernilai 0,190

2. Pengaruh langsung Ukuran Perusahaan terhadap Struktur Modal bernilai 0,177

3. Pengaruh langsung dari Struktur Modal terhadap Nilai Perusahaan bernilai 0,543.

Analisis jalur (path analysis) pengaruh tidak langsung, yaitu X2 melalui $\mathrm{Z}$ terhadap $\mathrm{Y}=0,177 \mathrm{x}$ $0,543=0,096$. Menurut Akdon (2017: 117) hasil dari pengujian secara tidak langsung tersebut dapat diketahui signifikansinya melalui perhitungan tabel $\mathrm{F}$ secara manual, dengan rumus berikut:

$$
\mathrm{F}=\frac{(\mathrm{n}-\mathrm{k}-1) \mathrm{R}^{2}}{\mathrm{k}\left(1-\mathrm{R}^{2}\right)}
$$

Keterangan :

$\mathrm{n} \quad=$ jumlah sampel

$\mathrm{k} \quad=$ jumlah variabel eksogen

$\mathrm{R}^{2}=\mathrm{R}_{\text {Square }}$

Jika $F_{\text {hitung }} \geq \mathrm{F}_{\text {tabel, }}$ maka tolak Ho dan ketika $\mathrm{F}$ hitung $\leq \mathrm{F}$ tabel terima Ho artinya data memberikan hasil yang tidak signifikan. Sebelum menggunakan rumus tabel F, ketahui terlebih dahulu $\mathrm{R}^{2}$, berikut perhitungannya:
https://ejurnal.stimi-bjm.ac.id/index.php/JRIMK

$$
\begin{array}{ll}
\mathrm{X} 2-\mathrm{Z}-\mathrm{Y} & =0,190+0,096 \\
\mathrm{R} & =0,286 \\
\mathrm{R}^{2} & =0,082
\end{array}
$$

Setelah hasil $\mathrm{R}^{2}$ sudah diketahui maka pengukuran signifikansi pengaruh tersebut dapat di perhitungakan dengan cara membandingkan nilai $\mathrm{F}_{\text {hitung }}$ dengan nilai $\mathrm{F}_{\text {tabel }}$ :

$$
\begin{aligned}
\mathrm{F} & =\frac{(\mathrm{n}-\mathrm{k}-1) \mathrm{R}^{2}}{\mathrm{k}\left(1-\mathrm{R}^{2}\right)} \\
\mathrm{F} & =\frac{(222-2-1) 0,082}{2(1-0,082)} \\
\mathrm{F} & =\frac{17,927}{1,836} \\
& =9,763
\end{aligned}
$$

Berdasarkan nilai $F_{\text {hitung }}$ tersebut dapat disimpulkan bahwa angka $(9,763>2,646)$ atau hasil tersebut memiliki nilai $F_{\text {hitung }}$ lebih besar dari nilai $F_{\text {tabel, }}$ artinya ada efek signifikan ukuran perusahaan pada nilai perusahaan melalui struktur modal, maka uji ini diterima.

\section{F. Uji Koefisien Determinasi \\ Tabel 7}

Uji Koefisien Determinasi

\begin{tabular}{ccc}
\hline $\mathrm{R}$ & $\mathrm{R}$ Square & Adjusted R Square \\
\hline 0,604 & 0,365 & 0,357 \\
\hline
\end{tabular}

Sumber: diolah 2019

Menurut Ghozali (2018:97) uji koefisien determinasi adalah uji yang digunakan untuk mengukur besar kemampuan variabel mampu menejelaskan variasi variabel terikat. Hasil Tabel 5.7, menghasilka nilai:

1. Nilai R dengan nilai sebesar 0,604 atau $60,4 \%$ menunjukkan tingkat hubungan antara variabel bebas dengan variabel terikat.

2. Nilai $R$ Square0,365 adalah $\mathrm{R}$ kuadrat, yang menunjukkan variabel bebas penelitian ini memiliki tingkat hubungan dengan variabel bebas sebesar 36,5\%. Menurut Ghozali (2018:97) setiap tambahan satu variabel bebas akan meningkatkan $R$ Square dengan catatan tidak perduli apakah variabel tersebut berpengaruh secara signifikan terhadap variabel terikat.

3. Menurut Ghozali (2018:97) nilai Adjusted $R$ Square adalah 0,357 yang menunjukkan nilai Adjusted $R$ Square bisa naik atau turun 
ketika satu variabel bebas ditambahkan kedalam model. Adjusted $R$ Square memperoleh hasil bahwa naik-turunnya variabel terikat $(\mathrm{Y})$ dipengaruhi oleh variabel bebas (X) $35,7 \%$.

\section{G. Implikasi Teoritis}

Berdasarkan perolehan hasil yang didapat, penelitian ini memberikan implikasi teoritis yaitu, tidak ada pengaruh risiko bisnis pada struktur modal. Pernyataan Ardana, Wahyudi dan Pangastuti (2015) alasan tidak ada pengaruh signifikan risiko bisnis pada struktur modal karena kebijakan manajemen dalam menggunakan utang tidak mempertimbangkan risiko yang ada, manajemen memutuskan menggunakan utang disesuaikan kebutuhan perusahaan untuk restrukturisasi ataupun untuk ekspansi.

Perolehan hasil uji memperlihatkan ada pengaruh positif ukuran perusahaan pada struktur modal. Perolehan ini mendukung packing order theory bahwa biaya untuk mendanai perusahaan pertama menggunakan dana internal, namun ketika aktivitas perusahaan semakin besar maka kebutuhan dana untuk membaiayai akan besar, menyebabkan perusahaan akan meggunakan dana eksternal berupa utang, ketika dana internal tidak mencukupi.

Pengaruh positif dan signifikannya Ukuran perusahaan pada nilai perusahaan telah mendukung teori signaling bahwa membesarnya ukuran perusahaan akan berdampak baik karena perusahaan akan semakin dikenal masyrakat, yang membuat investor tertarik untuk berinvestasi. Penelitian ini mendaptkan hasil tidak ada pengarauh risiko bisnis pada nilai perusahaan. Pernyataan Ardana, Wahyudi dan Pangastuti (2015) mengapa tidak ada pengaruh yang signifikan risiko bisnis pada nilai perusahaan karena risiko bisnis tidak memberikan dampak pada keputusan penggunaan utang oleh perusahaan.

Struktur modal menghasilkan hasil ada pengaruh positif yang signifikan pada nilai perusahaan. Hal ini memperlihatkan sejalannya hasil dengan teori Trade off theory yakni dengan menggunakan utang membuat semkin meningkatkannya nilai perusahaan selama struktur modal masih dbawah titik optimalnya.

\section{H. Implikasi Manajerial}

Hasil penelitian ini memberikan implikasi manajerial bahwa perusahaan perlu memperhatikan ukuran perusahaan waktu meningkatkan nilai peusahaan. Prosfek baik atau tidak kedepannya yang dimiliki perusahaan dapat dilihat dari ukuran perusahaannya yang berfungsi untuk menarik minat para investor agar menanamkan modalnya diperusahaan.

Perusahaan sebaiknya melihat sisi struktur modal saat meningkatkan nilai perusahaan. Pengelolaan struktur modal yang baik, maka akan mengungkan perusahaan dan juga membuat nilai perusahaan meningkat sehingga para investor juga tertarik untuk menanamkan sahamnnya diperusahaan.

\section{PENUTUP}

\section{Simpulan}

Berdasarkan pada hasil dari data yang dianalisis dan dari pembahasan penelitian, kesimpulannya adalah:

1. Pengaruh dari riisiko bisnis tidak signifikan pada struktur modal. Penyebab risiko bisnis tidak memberikan pengaruh karena setiap penambahan ataupun keputusan menggunakan utang tidak ada dampaknya pada perusahaan.

2. Pengaruh ukuran perusahaan yaitu positif signifikan pada struktur modal. Perolehan hasil searah dengan teori packing order theory yang menyatakan bahwa jika kebutuhan dana internal belum cukup untuk kegunaan danaaktivitas perusahaan maka perusahaan akan meningkatkan dana dari luar perusahaan.

3. Pengaruh risiko bisnis tidak ada dan tidak signifikan terhadap nilai perusahaan, karena kesimpulannya Ketika risiko bisnis terjadi penurunan ataupun kenaikan tidak ada dampak terhadap nilai perusahaan.

4. Pengaruh ukuran perusahaan yaitu positif dan juga signifikan terhadap nilai perusahaan. perolehan hasil searah dengan teroi signaling yang menyatakan bertambah besarnya ukuran perusahaan membuat daya Tarik perusahaan akan menarik juga bagi investor agar berinvestasi.

5. Pengaruh struktur modal yaitu positif terhadap nilai perusahaan. hasil ini juga searah dengan trade off theory yang menyatakan bahwa masa pemutusan penggunaan utang, berdampak kepada naiknya nilai perusahaan, selama penggunaan utangnnya berada dibawah titik maksimalnya.

6. Pengaruh signifikan risiko bisnis tidak ada terhadap nilai perusahaan melalui struktur 
https://ejurnal.stimi-bim.ac.id/index.php/JRIMK

modal. Perolehan hasil ini dinyatakan bahwa mediasi struktur modal tidak mampu membuat risiko bisnis memberikan pengaruh terhadap nilai perusahaan.

7. Pengaruh ukuran perusahaan yaitu positif signifikan terhadap nilai perusahaan melalui struktur modal. Hasil ini mengatakan bahwa mediasi struktur modal mampu memberikan dampak pada nilai perusahaan.

\section{Saran}

Peneliti ini memberikan saran dari perolehan hasil yang didapat, sebagai berikut:

1. Bagi Penelitian

Peneliti selanjutnya sebaiknya lebih memperluas keterbatasan dalam penelitian ini dengan menambah atau mengganti variabel risiko bisnis dengan variabel lain karena pada penelitian ini tidak ada pengaruh bisnis terhadap nilai perusahaan.

2. Bagi perusahaan

1. Meningkatkan ukuran perusahaan, perusahaan harus mampu meningkatkan aktivitas didalam perusahaan seperti memperbanyak produksi barang dan penjualan persediaan sebanyak mungkin dan jika perusahaan melakukan ekspansi, contohnya ingin menambah anak perusahaan disuatu daerah, maka perusahaan harus mengetahui lokasi mana yang cocok untuk membangun perusahaan. Seperti mengenal budaya lingkungan, kondisi ekonomi dan lain sebagainya. Pada intinya dengan ukuran perusahaan yang lebih ditingkatkan, akan membuat perusashaan memperoleh untung yang lebih besar.

2. Struktur modal lebih ditingkatkan karena proporsi antara utang dan modal adalah bagian dari struktur modal, dana yang telah digunakan oleh perusahaan, baik dana yang bersifat internal maupun eksternal agar kesimbangan return yang diharpakan oleh perusahan maupun investor dapat terpenuhi.

\section{DAFTAR PUSTAKA}

Ardana, Wahyudi \& Pangastuti 2015. Analisis Pengaruh Risiko Bisnis, Frim Size, Pertumbuhan Struktur Modal dan Dampaknya Pada Nilai Perusahaan, Universitas Diponegoro.
Arfan Ikhsan, Sukma Lesmana. Atma Hayat. (2015). Teori Akuntansi. Cetakan Pertama. Citapustaka Media, Bandung.

Ayuba, Bamble \& Sulaiman 2019, Effects of Financia Performance, Capital Structure and Firm Size on Firm's Value of Insurance Comapines in Nigeria. NNDC-ICAN, Nigeria

Bambang, S 2014, Pengungkapan wajib perusahaan publik: kajian teori dan empiries, Universitas brawijaya press, Malang.

Brigham, H 2013. Dasar-dasar Manajemen Keuangan, Selemba Empat, Jakarta.

Coung \& Canh (2012). The Effect of Capital on Firm Value of Vietnam's Seafood Processing Enterprise. Faculty of Accounting and Finance \& Faculty of Banking and Finance, Vietnam.

Dewi \& Sudiartha (2017). Pengaruh Profitabilitas, Ukuran Perusahaan dan Pertumbuhan Aset Terhadap Struktur Modal dan Nilai Perusahaan. Fakultas Ekonomi dan Bisnis. Universitas Udayana, Bali.

Dewi \& Sujana (2019), Pengaruh Likuiditas, Pertumbuhan Penjualan dan Risiko Bisnis Terhadap Nilai Perusahaan. Fakultas Ekonomi dan Bisnis. Universitas Udayana, Bali.

Dewi \& Wirajaya (2013). Pengaruh Struktur Modal, Profitabilitas dan Ukuran Perusahaan Pada Nilai Perusahaan. Fakultas Ekonomi dan Bisnis. Universitas Udayana, Bali.

Fenty, F 2017, Kesehatan bank, kebijakan dividem dan nilai perusahaan: teori dan kajian empiries, RV Pustaka horizon, Samarinda.

Hardono, M 2009, Intisari manajemen keuangan, Grasindo

Hery, 2017 Kajian Riset Akuntansi. PT Gramedia, Jakarta.

Husnan, S 2015. Dasar-dasar Manajemen Keuangan, UPP STIM YKPN, Jakarta

https://www.kajianpustaka.com/2017/11/pengertianjenis-dan-pengukuran-nilai-perusahaan.html.

https://repository.widyatama.ac.id/xmlui/bitstream/ha ndle/123456789/7273/Bab\%202.pdf?sequen ce $=10$. [Tanggal akses: 12 Februari 2019]

https://sudutekonomi.blogspot.co.id/2017/11/pengerti an-ukuran-perusahaan.html. [Tanggal akses: 12 Februari 2019]

https://statmat.id/ukuran-sampel-penelitian/. [Tanggal akses: 12 Februari 2019] 
Imam, G 2011. Aplikasi Analisis Multivarite dengan Program IBM SPSS 19, Edisi Lima, Universitas Diponegoro, Semarang.

Irham, F 2018, Pengantar Manajemen Keuangan, Alfabeta, Bandung

Jogiyanto, H 2017, Teori portofolio dan analisis investasi, BPFE, Yogyakarta.

Kasmir. 2015, Analisis Laporan Keuangan. Edisi Pertama, Cetakan Keenam, Rajawali Pers, Jakarta.

Margaretha, F 2014, Dasar-dasar Manajemen Keuangan, Dian Rakyat, Jakarta.

Mamduh, H 2016. Manajemen Keuangan. Edisi kedua. Cetakan Pertama. BPEE, Yogyakarta.

Minh Ha \& Minh Thai 2017. Impact of Capital Strukture and Holdings on Firms Value : Case of Firms Listed on the Ho chai Minh Stock Exchange. Sai Gon Technology University. Vietnam.

Mohammed 2012. Impact of Bussines Risk on Corporate Capital Structure Publicly-Listed Negeria Companies. Departement of Business Administration and Enterpreneurship Bayero Iniversity. Nigeria.

Prasetyorini 2012. Pengaruh Ukuran Perusahaan, Leverage, Orice Earning Ratio dan Profitabilitas terhadap Nilai perusahaan. Fakultas Ekonomi, Surabaya.

Priya, Nimalathasan \& Piratheepan 2015. Impact of Capital Structure on The Firm Value: Case Study of Listed Manufacturing Companies Sri Lanka. Universitas of Jaffna, Sri Lanka.

Puspitaningrum 2016. Pengaruh Risiko Bisnis, Profitabilitas dan Leverage Terhadap Nilai Perusahaan. Fakultas Ekonomika dan Bisnis. Universitas Gajah Mada, Yogyakarta.

Regina, Maryam \& Jacky 2015. Pengaruh struktur modal, ukuran perusahaan dan risiko perusahaan terhadap nilai perusahaan pada sub sektor plastik dan pengemasan di BEI

Riduwan 2017. Cara Menggunakan dan Memakai Path Analysis. Alfabeta, Bandung.

Riyanto, Bambang 2012. Dasar-dasar Pembelanjaan Perusahaan. BPFE, Yogyakarta.

Rudangga \& Sudiarta 2016. Pengaruh Ukuran Perusahaan Leverage dan Profitabilitas Terhadap Nilai Perusahaan. Fakultas Ekonomi dan Bisnis. Universitas Udayana, Bali.
Sawitri \& Lestari 2015. Pengaruh Risiko Bisnis, Ukuran Perusahaan dan Pertumbuhan Penjualan Terhadap Struktur Modal. Fakultas Ekonomi dan Bisnis. Universitas Udayana, Bali.

Septiani \& Suaryana 2018. Pengaruh Profitabilitas, Ukuran Perusahaan, Struktur Aset, Risiko Bisnis dan Likuiditas pada Struktur Modal. Fakultas Ekonomi dan Bisnis. Universitas Udayana, Bali.

Suadnyana \& Wiagustini 2013. Pengaruh Risiko Bisnis dan Pertumbuhan Perusahaan Terhadap Struktur Modal dan Nilai Perusahaan. Studi Manajemen Program Pascasarjana. Universitas Udayana, Bali.

Sujarweni, V,W. 2018. Kupas Tuntas Penelitian Akuntansi Dengan SPSS, Pustaka Baru Press, Yogyakarta.

Uma, S 2013. Metodelogi Penelitian untuk Bisnis. Selemba Empat, Jakarta.

Winata 2018. Pengaruh Struktur Modal, Ukuran Perusahaan, Profitabilitas dan Leverage Terhadap Nilai Perusahaan. Fakultas Ekonomi dan Bisnis, Surakarta.

\section{Profil Penulis:}

1. Mahfudzah Hidayati Rahmi

Program Magister Manajemen, Fakultas

Ekonomi dan Bisnis, Universitas Lambung

Mangkurat)

Email: mhrmimi27@gmail.com

2. Fifi Swandari

Fakultas Ekonomi dan Bisnis, Universitas

Lambung Mangkurat

Email: fifiswandari71@gmail.com 